\title{
La imprescriptibilidad del derecho a obtener reparación integral de las víctimas de delitos de lesa humanidad
}

The imprescriptibility of the right to obtain full reparation for victims of crimes against bumanity

A imprescriptibilidade do direito de obter reparação integral das vítimas dos crimes de bumanidade lesa

L'imprescriptibilité du droit d'obtenir une réparation integrale pour les victimes des crimes contre l'bumanité

全面获得对莱萨人的犯罪受害者的赔偿权不容侵犯

\author{
Nerina Da $\operatorname{Rin}^{1}$ \\ Universidad de Buenos Aires - Argentina
}

Revista Derechos en Acción ISSN 2525-1678/ e-ISSN 2525-1686

Año 5/Nº 14, Verano 2019-2020 (21 diciembre a 20 marzo), 547-557

DOl: https://doi.org/10.24215/25251678e368

Recibido: 01/12/2019

Aprobado: 01/02/2020

Resumen: La Corte Interamericana de Derechos Humanos ha establecido un nuevo estándar convencional en reciente jurisprudencia: la imprescriptibilidad del derecho a reparación integral en los aspectos civiles del daño ocasionado por delitos de lesa humanidad, a las víctimas de delitos de lesa humanidad. Ello en consonancia con la evolución del derecho internacional de los derechos humanos.

\footnotetext{
1 La autora es Abogada (UCA), doctoranda (UBA). Profesora Adjunta de Derechos Humanos y Garantías. Medios de Protección del Sistema Interamericano de Derechos Humanos. Facultad de Derecho UBA. Directora Ejecutiva del Centro de Análisis y Aplicación de Control de Convencionalidad dela Defensoría del Pueblo de la Ciudad Autónoma de Buenos Aires.
} 
Palabras claves: prescripción; reparación integral; delitos; lesa humanidad

Abstract: The Inter-American Court of Human Rights has established a new conventional standard in recent jurisprudence: the non-applicability of statutory limitations to the right to full reparation in the civil aspects of the damage caused by crimes against humanity, to the victims of crimes against humanity. This is in line with the evolution of international human rights law.

Keywords: statute of limitations; integral reparation; crimes; lesa humanity

Resumo: A Corte Interamericana de Direitos Humanos estabeleceu um novo padrão convencional em jurisprudência recente: a imprescritibilidade do direito à reparação integral em os aspectos civis do dano causado por crimes contra a humanidade às vítimas de crimes contra a humanidade. Isso de acordo com a evolução do direito internacional dos direitos humanos.

Palavras-chave: prescrição; reparação integral; crimes; lesa humanidade

Résumé: La Cour interaméricaine des droits de I'homme a établi un nouveau standard dans la jurisprudence récente: I'imprescriptibilité du droit à une réparation civil globale de ces dommages causés par les crimes contre l'humanité aux ses victimes. Ceci, en ligne avec l'évolution du droit international des droits de l'homme.

Mots clés: prescription; réparation integrale; crimes; crimes contre I'humanité

摘要：美洲人权法院在最近的判例中建立了一个新的常规标准:对 危害人类罪受害者的危害人类的民事方面的全面赔偿权是不可剥夺 的。这与国际人权法的发展保持一致。

关键词: 处方, 全面维修, 犯罪, 人类社会

\section{Introducción}

El Derecho Internacional se ocupa en sus diferentes perspectivas y enfoques de las cuestiones relativas a los delitos de lesa humanidad. ${ }^{2}$

2 Delitos de lesa humanidad: Estatuto de Tribunal Militar Internacional de Nüremberg: ....art. 6 "....c) CRIMENES CONTRA LA HUMANIDAD: A saber, el asesinato, la exterminación, 
Así, desde el Derecho Internacional de los Derechos $\mathrm{Hu}-$ manos se atienden la cuestiones que tutelan y protegen los derechos de las víctimas de estos delitos: el derecho a saber o derecho a la información, el amparo judicial o derecho de acceso a la justicia y a las garantías judiciales, el derecho a obtener reparación integral que involucra: restitución, indemnización, rehabilitación, satisfacción y garantías de no repetición ${ }^{3}$.

Por su parte, el Derecho Penal Internacional persigue a los autores de delitos internacionales, ya sean de lesa humanidad, genocidio, apartheid, de agresión, o crímenes de guerra y aplica penas a individuos.

Cada uno de estos ámbitos del derecho internacional, si bien tienen finalidades específicas, son también complementarias, ya que ambas persiguen la no repetición de estos gravísimos crímenes contra la humanidad.

esclavización, deportación y otros actos inhumanos cometidos contra población civil antes de la guerra o durante la misma; la persecución por motivos políticos, raciales o religiosos en ejecución de aquellos crímenes que sean competencia del Tribunal o en relación con los mismos, constituyan o no una vulneración de la legislación interna de país donde se perpetraron. Aquellos que lideren, organicen, inciten a la formulación de un plan común o conspiración para la ejecución de los delitos anteriormente mencionados, asi como los cómplices que participen en dicha formulación o ejecución, serán responsables de todos los actos realizados por las personas que sea en ejecución de dicho plan." http://www.cruzroja.es/principal/ documents/1750782/1852538/estatuto_del_tribunal_de_nuremberg.pdf/20090fa2-e5bf447a-aa96-612403df2a66 Convención sobre la imprescriptibilidad de los crímenes de guerra y de los crímenes de lesa humanidad. Adoptada por la Asamblea General de la Naciones Unidas, en su Resolución 2391 (XXIII), de 26 de noviembre de 1968. Entrada en vigor internacional el 11 de noviembre de 1970. "Artículo 1.... b) Los crímenes de lesa humanidad cometidos tanto en tiempo de guerra como en tiempo de paz, según la definición dada en el Estatuto del Tribunal Militar Internacional de Nüremberg, de 8 de agosto de 1945, y confirmada por las resoluciones de la Asamblea General de las Naciones Unidas 3 (I) de 13 de febrero de 1946 y 95 (I) de 11 de diciembre de 1946, así como la expulsión por ataque armado u ocupación y los actos inhumanos debidos a la política de apartheid y el delito de genocidio definido en la Convención de 1948 para la Prevención y la Sanción del Delito de Genocidio aun si esos actos no constituyen una violación del derecho interno del país donde fueron cometidos. " También ver Estatuto de Roma de la Corte Penal Internacional, articulo 7 y concordantes.

3 Resolución 60/147 de la Asamblea General de las Naciones Unidas, del 16 de diciembre de 2005. Principios y directrices básicos sobre el derecho de las víctimas de violaciones manifiestas a normas del derecho internacional de los derechos humanos y de violaciones graves de derecho internacional humanitario a interponer recursos y obtener reparaciones. Principio 15. 


\section{Evolución del derecho a la reparación}

En materia del reconocimiento de los derechos humanos podemos señalar una constante evolución, con el fin de asegurar más derechos a mayor número de personas. Esta es una característica de los derechos humanos y se conoce como su desarrollo progresivo. Este progreso consolida los derechos humanos reconocidos que, entonces, ya no pueden ser reducidos o desconocidos. Esto es consecuencia del principio pro persona y de prohibición de regresividad de los derechos humanos.

En este sentido, el derecho a reparación integral de las víctimas de delitos de lesa humanidad ha evolucionado con el tiempo y ha consolidado su reconocimiento y ejercicio. Esta evolución se pone de manifiesto en el reciente fallo de la Corte Interamericana de Derechos Humanos (Corte IDH), en el Caso Órdenes Guerra y Otros vs. Chile. Sentencia de 29 de Noviembre de 2018.

La Corte hizo un análisis sistemático, teleológico y evolutivo del derecho a reparación integral de las víctimas de delitos de lesa humanidad y estableció estándares regionales que se fundan en los desarrollos actuales del derecho internacional de los derechos humanos.

La cuestión central en este caso fue establecer si el estado demandado, la República de Chile, era responsable internacionalmente por haber aplicado la prescripción civil en los casos de reclamos de indemnizaciones civiles por las consecuencias de delitos de lesa humanidad. Lo que dejó sin reparación a las víctimas en el sistema judicial chileno. La falta de tutela primaria abrió la posibilidad de acceso a la justicia en el sistema subsidiario de medios de protección, conforme está previsto en la Convención Americana de Derechos Humanos. En este proceso la Corte IDH dictó la sentencia que a continuación se analiza.

El análisis evolutivo que la Corte IDH realizó, estableció que la comunidad internacional está interesada tanto en la persecución penal de estos crímenes internacionales, como en la reparación integral a las víctimas de tales delitos incluyendo la indemnización civil. 
El interés destacado dentro de la reparación integral por tales gravísimos delitos forma parte del orden público internacional que obliga a los estados parte del sistema interamericano a aplicar el nuevo estándar en ejercicio del control de convencionalidad.

\subsection{La imprescriptibilidad del derecho a reparación integral en los delitos de lesa humanidad como norma imperativa del derecho internacional}

La persecución de los delitos de lesa humanidad resulta ser una norma imperativa del derecho internacional o norma de ius cogens $^{4}$. Los estados no pueden apartarse de ella sin incurrir en responsabilidad internacional. Por lo que se puede afirmar que las reglas del derecho de gentes sobre los delitos de lesa humanidad forman parte del orden público internacional.

De modo tal que si se traza una línea temporal sobre la evolución de este principio general, hoy estándar, desde su aplicación desde 1945 en el Estatuto del Tribunal Internacional Militar de Nüremberg, que luego se reitera y amplia en la Convención de las Naciones Unidas sobre la Imprescriptibilidad de los Crímenes de Guerra y de Lesa Humanidad, en el Estatuto de Roma de la Corte Penal Internacional, también en 2005 en los "Principios y Directrices Básicos sobre el Derecho de las Víctimas de Violaciones Manifiestas de las Normas Internacionales de Derechos Humanos y de Violaciones Graves del Derecho Internacional Humanitario a Interponer Recursos y a Obtener Reparaciones" ${ }^{5}$ en el "Conjunto de principios actualizado para

\footnotetext{
4 Convención de Viena sobre Derechos de los Tratados, adoptada el 23 de mayo de 1969. Artículo 53 "Tratados que están en oposición con una norma imperativa del derecho internacional general (ius cogens). ...Para los efectos de la presente Convención, una norma imperativa del derecho internacional general es una norma aceptada y reconocida por la comunidad internacional de Estados en su conjunto como norma que no admite acuerdo en contrario y que solo puede ser modificada por una norma ulterior de derecho internacional general que tenga el mismo carácter".

5 Naciones Unidas, Resolución 60/147 de la Asamblea General.
} 
la protección y la promoción de los derechos humanos mediante la lucha contra la impunidad"6.

El Estatuto de Roma de la Corte Penal Internacional ${ }^{7}$, en su preámbulo afirma,

“.. que los crímenes más graves de trascendencia para la comunidad internacional en su conjunto no deben quedar sin castigo y que, a tal fin, hay que adoptar medidas en el plano nacional e intensificar la cooperación internacional para asegurar que sean efectivamente sometidos a la acción de la justicia..."

Los Principios Básicos de Protección a las Víctimas de Violaciones Manifiestas de las Normas Internacionales de Derechos Humanos y de Violaciones Graves del Derecho Internacional Humanitario a Interponer Recursos y a Obtener Reparaciones, se enfocan en los principios reparatorios. Señalan estándares que los estados parte del sistema de las Naciones Unidas deben cumplir en sus respectivas jurisdicciones cuando se trate de la reparación integral de los daños sufridos por las víctimas de delitos de lesa humanidad.

En este sentido, sobre la prescripción, en el principio 6 se establece que:

"6. Cuando así se disponga en un tratado aplicable oforme parte de otras obligaciones jurídicas internacionales, no prescribirán las violaciones manifiestas de las normas internacionales de derechos humanos ni las violaciones graves del derecho internacional humanitario que constituyan crimenes en virtud del derecho internacional".

Luego, en el principio 15 se establece la obligación de reparar el daño de manera adecuada:

6 Naciones Unidas Distr. GENERAL E/CN.4/2005/102/Add.1 8 de Febrero de 2005. Informe de Diane Orentlicher, experta independiente encargada de actualizar el conjunto de principios para la lucha contra la impunidad. Conjunto de principios actualizado para la protección y la promoción de los derechos humanos mediante la lucha contra la impunidad.

7 Estatuto de Roma de la Corte Penal Internacional, aprobado en Roma el 17 de julio de 1998. 
"15. Una reparación adecuada, efectiva y rápida tiene por finalidad promover la justicia, remediando las violaciones manifiestas de las normas internacionales de derechos humanos o las violaciones graves del derecho internacional humanitario. La reparación ba de ser proporcional a la gravedad de las violaciones y al daño sufrido. Conforme a su derecho interno y a sus obligaciones jurídicas internacionales, los Estados concederán reparación a las víctimas por las acciones $u$ omisiones que puedan atribuirse al Estado y constituyan violaciones manifiestas de las normas internacionales de derechos humanos o violaciones graves del derecho internacional bumanitario. Cuando se determine que una persona física o jurídica u otra entidad está obligada a dar reparación a una víctima, la parte responsable deberá conceder reparación a la víctima o indemnizar al Estado si éste hubiera ya dado reparación a la víctima..."

En materia de impunidad, los principios de Naciones Unidas también se ocupan de la prescripción y la imprescriptibilidad:

El principio 23, “...La prescripción no se aplicará a los delitos graves conforme el derecho internacional que sean por naturaleza imprescriptibles. Cuando se aplica, la prescripción no podrá invocarse en las acciones civiles o administrativas entabladas por las víctimas para obtener reparación...".

Luego, en el principio 32, referido a los procedimientos para obtener reparación, se indica que

"32. Tanto por la vía penal como por la vía civil, administrativa o disciplinaria, toda víctima debe tener la posibilidad de ejercer un recurso accesible que incluirá las restricciones que a la prescripción impone el principio 23."

Las reglas centrales sobre prescripción en este sistema de principios son

- No puede correr la prescripción cuando faltan los recursos eficaces del estado a disposición de las víctimas; 
- Imprescriptibilidad de los delitos graves del derecho internacional, como norma imperativa del derecho internacional;

- Imprescriptibilidad del derecho a resarcimiento por daños civiles y no caducidad de las acciones civiles o administrativas para obtener reparación por parte de las víctimas de delitos de lesa humanidad.

La responsabilidad estatal por la falta de amparo judicial de los delitos de lesa humanidad y sus consecuencias, tiene su fuente jurídica en el derecho internacional, tanto en los principios generales, como la costumbre internacional, los tratados, la jurisprudencia y la doctrina.

\section{Jurisprudencia internacional: Corte IDH. Caso Órdenes Guerra y Otros vs. Chile. Sentencia de 29 de noviembre de 2018}

Esta sentencia ha esclarecido los estándares convencionales para la protección del derecho a la reparación de las víctimas de los delitos de lesa humanidad.

La Corte recordó, en esta oportunidad, que en su jurisprudencia anterior se ha referido al amplio contenido del derecho de acceso a la justicia y a las garantías judiciales reconocidas en la $\mathrm{CADH}$ en los artículos 8.1. y 25., en relación con los artículos 1.1. y 2.

"77. En particular, en casos de graves violaciones de derechos humanos y de manifiesta obstrucción de justicia, este tribunal ha considerado que "en ciertas circunstancias el Derecho Internacional considera inadmisible e inaplicable la prescripción [penal], así como las disposiciones de amnistía y el establecimiento de excluyentes de responsabilidad, a fin de mantener vigente en el tiempo el poder punitivo del Estado de conductas cuya gravedad hacen necesaria su represión para evitar que vuelvan a ser cometidas". Tales institutos jurídicos o disposiciones son inadmisibles cuando "pretendan impedir la investigación y sanción de los responsables de las violaciones graves de los derechos humanos tales como la tortura, las ejecuciones sumarias, extralegales $\mathrm{o}$ arbitrarias $\mathrm{y}$ 
las desapariciones forzadas, todas ellas prohibidas por contravenir derechos inderogables reconocidos por el Derecho Internacional de los Derechos Humanos"8.

"78. En relación con lo anterior este Tribunal es consciente de los desarrollos que existen en el Derecho Internacional en materia de aplicabilidad del instituto jurídico de la prescripción a acciones judiciales para obtener reparaciones frente a graves violaciones de derechos humanos."

En considerandos siguientes el tribunal analizó sistemática, evolutiva y teleológicamente, el derecho a reparación de las víctimas de graves violaciones de derechos humanos, y en especial enfocó el instituto de la prescripción en estos casos. Señaló, tanto el cambio en la jurisprudencia chilena, sobre la actual aplicación de la imprescriptibilidad, como también el caso del Consejo de Estado de Colombia, que ha inaplicado el plazo de caducidad de las acciones por daños, ponderando entre la seguridad jurídica y el imperativo de brindar reparación del daños ocasionado por delitos de lesa humanidad, cede el primero.

En este contexto regional también hizo notar que la reforma del Código Civil y Comercial de la Argentina en vigencia, establece en su artículo 2561 que las acciones civiles derivadas de delitos de lesa humanidad son imprescriptibles.

Destacó en los antecedentes del caso a los argumentos de la Comisión Interamericana de Derechos Humanos, (CIDH), que consideró:

"88. La razón de ser de la inconvencionalidad de aplicar la figura de la prescripción de la acción penal en casos de

8 Corte Interamericana de Derechos Humanos Caso Órdenes Guerra y Otros vs. Chile. Sentencia de 29 de noviembre de 2018 (Fondo Reparaciones y Costas)

Corte IDH Caso Ibsen Cárdenas e Ibsen Peña Vs. Bolivia. Fondo Reparaciones y Costas, Sentencia del 1 de septiembre de 2010. Serie C N² 217, parr. 207.

Corte IDH Caso Barrios Altos Vs Perú. Sentencia del 14 de marzo de 2001 Fondo, Reparaciones y costas. Serie C N 75 , parr 41, y Caso Herzog y otros vs. Brasil. Exce3pciones preliminares, Fondo Reparaciones y Costas, Sentencia del 15 de marzo de 2018. Serie CN353, parr. 288. 
graves violaciones de derecho bumanos se relaciona con el carácter fundamental que tiene el esclarecimiento de los hechos y la obtención de justicia para las víctimas. Por ello la Comisión señaló que no encuentra razones para aplicar un estándar distinto a un aspecto fundamental como es la reparación en este tipo de casos, por lo cual las acciones judiciales de reparación del daño causado por crimenes internacionales no debería estar sujetar a prescripción. En razón de las fechas en que ocurrieron o comenzaron a ocurrir, la Comisión consideró que las violaciones primarias respecto de las cuales las víctimas de este caso buscan reparación, todas a partir de septiembre de 1973, hacen parte de los crímenes de lesa humanidad cometidos durante la dictadura militar, por la cual la aplicación de la figura de la prescripción a sus acciones de reparación constituyó un obstáculo en el acceso afectivo a la justicia para hacer efectivo su derecho a ser reparadas.".

La Corte IDH sostuvo que:

95. “...para considerar imprescriptibles las acciones civiles de reparaciones por daños ocasionados en bechos calificados o calificables como crimenes contra la humanidad, con base en la jurisprudencia de la Corte Suprema [de Chile], son aplicables a cualquier acción civil, independientemente de si esta es resarcitoria en el marco de un proceso penal o si es una demanda en la vía civil propiamente dicha. Es decir, tal imprescriptibilidad se justifica en la obligación del Estado de reparar por la naturaleza de los hechos y no depende por ello del tipo de acción judicial que se busque hacer valer'... (96.) "...la Comisión consideró que las vías de reparación administrativa y judicial son complementarias y no excluyentes....".

Se configura así un nuevo estándar convencional que debe ser tenido en cuenta al momento de aplicar la Convención Americana de Derechos Humanos y que resulta obligatorio para los estados parte del Sistema Interamericano de Derechos Humanos. 
Lo que implica que no es posible para los Estados parte de la CADH, sus tribunales y demás órganos y poderes estatales, desconocer la imprescriptibilidad del derecho a la reparación civil por daños ocasionados en hechos calificados o calificables como crimen contra la humanidad, independientemente de si esta es resarcitoria de un proceso penal o si es una demanda independiente en la vía civil.

El estándar del caso Ordenes Guerra y otros vs. Chile., se constituye en fuente del derecho internacional de los derechos humanos en el orden regional y debe ser aplicado en ejercicio del control de convencionalidad, obligación de todos los Estados parte del sistema interamericano.

El reconocimiento del derecho imprescriptible a la reparación integral por crímenes contra la humanidad nace de un interés internacional específico, orden público internacional, que está expresado en tratados, normas, principios generales jurisprudencia y doctrina, y que tiene especial interés en prevenir las repeticiones de estos delitos gravísimos. 